\title{
Prediction of postpartum diabetes in women with gestational diabetes mellitus
}

\author{
M. Ekelund • N. Shaat • P. Almgren • L. Groop • \\ K. Berntorp
}

Received: 14 July 2009 /Accepted: 2 November 2009/Published online: 2 December 2009

(C) Springer-Verlag 2009

\begin{abstract}
Aims/hypothesis We studied the incidence of postpartum diabetes after gestational diabetes mellitus and investigated biochemical and clinical predictors of postpartum diabetes. Methods We monitored 174 women with gestational diabetes by performing oral glucose tolerance tests during pregnancy as well as 1,2 and 5 years postpartum. Women who developed impaired fasting glucose, impaired glucose tolerance or diabetes were compared with women who remained normoglycaemic at 5 years. Insulinogenic index, disposition index and HOMA-beta cell index were used to assess beta cell function; insulin resistance was estimated by HOMA index of insulin resistance.

Results At 5 years postpartum, 30\% of the women had developed diabetes and 51\% some form of abnormal glucose tolerance. Women who developed diabetes had higher fasting glucose and $\mathrm{HbA}_{1 \mathrm{c}}$ during pregnancy than those who remained normoglycaemic. They also had lower HOMAbeta cell index, insulinogenic index and disposition index than the normoglycaemic women. $\mathrm{HbA}_{1 \mathrm{c}}$ and fasting glucose during pregnancy as well as the number of previous pregnancies and family history of diabetes were independent predictors of postpartum diabetes. $\mathrm{HbA}_{1 \mathrm{c}} \geq 4.7 \%$ (Swedish Mono S) or $\geq 5.7 \%$ (National Glycohemoglobin Standardization Program) and fasting blood glucose $\geq 5.2 \mathrm{mmol} / 1$ were associated with a four- to sixfold increased risk.
\end{abstract}

\footnotetext{
M. Ekelund $(\square)$

Department of Internal Medicine, Hospital of Helsingborg,

SE-251 87 Helsingborg, Sweden

e-mail: magnus.ekelund@skane.se

N. Shaat $\cdot$ P. Almgren $\cdot$ L. Groop $\cdot$ K. Berntorp

Department of Endocrinology, Malmö University Hospital,

Lund University,

Malmö, Sweden

Conclusions/interpretation Among women with gestational diabetes mellitus, those at risk of future diabetes can be identified by $\mathrm{HbA}_{1 \mathrm{c}}$ and fasting glucose values in the upper normal range during pregnancy. A family history of diabetes and previous pregnancies further increase this risk.

Keywords Beta cell dysfunction - Disposition index . GAD-antibodies · Gestational diabetes mellitus $\cdot \mathrm{HbA}_{1 \mathrm{c}}$. HOMA · Insulinogenic index · Insulin resistance · OGTT · Postpartum diabetes
Abbreviations
IFG Impaired fasting glucose
IGT Impaired glucose tolerance
NGSP National Glycohemoglobin Standardization Program
NGT Normal glucose tolerance

\section{Introduction}

Gestational diabetes mellitus, which affects about $2 \%$ of pregnant women in Sweden [1], increases the risk of postpartum diabetes, particularly type 2 [2]. Women with gestational diabetes mellitus thus represent a high-risk group, in which interventions to prevent or delay diabetes make sense. Several risk factors for postpartum diabetes have been identified, some of which are potentially modifiable whereas others are not [3, 4]. It would be desirable to identify women at greatest risk of postpartum diabetes during their pregnancy.

The aims of the present study were to prospectively determine the 5 year incidence of diabetes after gestational diabetes mellitus and to identify predictors of postpartum diabetes. 


\section{Methods}

Study population In southern Sweden all pregnant women are offered a $75 \mathrm{~g}$ OGTT after an overnight fast at their local antenatal clinic in pregnancy weeks 27 to 28 and also in weeks 10 to 12 if they have a first-degree family history of diabetes or have had previous gestational diabetes mellitus. A $2 \mathrm{~h}$ capillary blood glucose $\geq 9 \mathrm{mmol} / \mathrm{l}$ is regarded as diagnostic proof of gestational diabetes mellitus [5]. The laboratory procedure using HemoCue devices (HemoCue, Ängelholm, Sweden) has shown a coefficient of variation of 3.1 to $3.7 \%$ [1].

All women diagnosed with gestational diabetes mellitus in our area are referred to the Department of Endocrinology for follow-up during pregnancy. Women referred between 1996 and 1999 were invited to take part in a 5-year follow-up programme. Out of 188 consecutive patients, 182 agreed to be enrolled. Eventually eight women were not included since a repeat OGTT at studystart could not be performed. Forty women did not participate in the final 5-year visit. Information on ten of these was obtained from patient records and the local diabetes registry, enabling seven to be classified as having diabetes and three as having normal glucose tolerance (NGT). Of the remaining 30 non-participators at 5 years, 18 were Swedish and 12 of non-Nordic origin. Baseline characteristics of the 144 participators and 30 non-participators were similar. Reasons for non-participation were moving from the area $(n=6)$, non-response $(n=5)$ and refusal $(n=19)$. Fifteen of those who refused to participate were Swedish.

Study design As soon as possible after referral a repeated $75 \mathrm{~g}$ OGTT was performed after an overnight fast. Venous samples for determination of blood glucose and insulin concentrations were drawn at $0,30,60,90$ and $120 \mathrm{~min}$. $\mathrm{HbA}_{1 \mathrm{c}}$, GAD-antibodies, weight and height were measured and BMI calculated. Information on family history of diabetes, number of previous pregnancies and ethnic origin was obtained. The population was grouped according to Swedish and non-Nordic origin. Women of non-Nordic origin were immigrants from different countries in Southern and Eastern Europe, Asia, South America and Africa, with Arabian women from the Middle East (36\%) and women from the former Yugoslavia (22\%) comprising the largest groups.

Insulin resistance was estimated as the HOMA insulin resistance index. Beta cell function was evaluated by the HOMA beta cell index [6] and by the insulinogenic index as the ratio of incremental insulin to glucose during the first $30 \mathrm{~min}$ of the OGTT, i.e. (insulin $30 \mathrm{~min}-$ insulin $0 \mathrm{~min}$ )/ (glucose $30 \mathrm{~min}$-glucose $0 \mathrm{~min}$ ) [7]. The disposition index was used to adjust insulin secretion for the degree of insulin resistance (insulinogenic index/HOMA of insulin resistance).

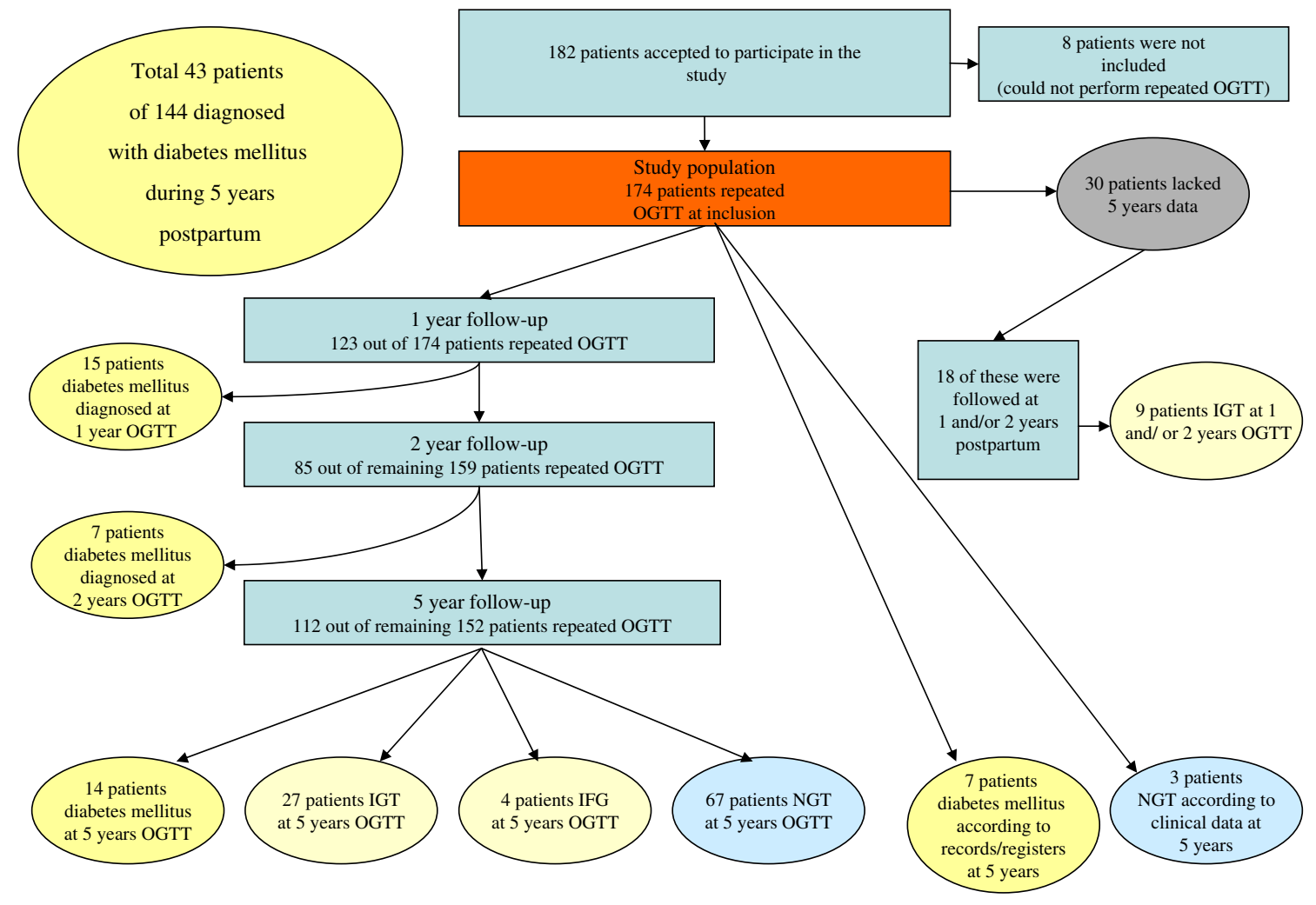

Fig. 1 Flow chart of the study population and results for disturbances of glucose metabolism at follow-up 
The procedure was repeated after 1 year (median 55 weeks postpartum, interquartile range 52-60 weeks) and 2 years (median 108 weeks postpartum, interquartile range 105-114 weeks), unless diabetes had been diagnosed. GADantibodies, $\mathrm{HbA}_{1 \mathrm{c}}$, LDL-cholesterol, HDL-cholesterol, total cholesterol, triacylglycerol and urate were analysed. BMI and WHR were calculated.

At 5 years (median 61 months postpartum, interquartile range 60-63 months) a $75 \mathrm{~g}$ OGTT was performed, unless diabetes had been diagnosed. $\mathrm{HbA}_{1 \mathrm{c}}$ was measured and BMI calculated.

Diagnostic criteria were according to WHO 1999 [8]. Informed consent was obtained from the patients and the Ethics Committee of Lund University approved the study protocol.
Assays Glucose was analysed using HemoCue devices. Serum insulin was measured by an enzyme-linked immunosorbent assay (Dako, Glostrup, Denmark) and $\mathrm{HbA}_{1 \mathrm{c}}$ by ion exchange chromatography [9], normal range 3.6 to $5.0 \%$. Cholesterol, HDL-cholesterol, triacylglycerol and urate were measured on an analyser (LX20; Beckman Coulter, Brea, CA, USA). LDL-cholesterol concentration was calculated using Friedewald formula [10]. GADantibodies were tested by radioimmunoassay as previously described [11].

Statistical analyses Data are presented as mean $\pm \mathrm{SD}$ or as median and interquartile range. ANOVA was used to test for differences between group means (symmetrically distributed variables) and Kruskal-Wallis was used to test

Table 1 Comparison of baseline characteristics in relation to glucose tolerance at 5 years follow-up

\begin{tabular}{|c|c|c|c|c|}
\hline \multirow[t]{2}{*}{ Characteristics } & \multicolumn{3}{|c|}{ Values per group at 5 years postpartum } & \multirow[t]{2}{*}{$p$ value } \\
\hline & NGT & IGT-IFG & Diabetes mellitus & \\
\hline$n$ & 70 & 31 & 43 & \\
\hline Age at delivery (years) & $31.0(4.6)$ & $32.0(5.9)$ & $31.6(5.8)$ & 0.6 \\
\hline BMI during pregnancy $\left(\mathrm{kg} / \mathrm{m}^{2}\right)$ & $27.0(25.8-29.9)$ & $29.3(26.2-32.0)$ & $30.9(27.1-32.9)$ & 0.02 \\
\hline Swedish origin, $n(\%)$ & $41(59)$ & $8(26)$ & $18(42)$ & 0.008 \\
\hline Relative(s) with diabetes, $n(\%)^{\mathrm{a}}$ & $34(49)$ & $17(55)$ & $30(70)$ & 0.09 \\
\hline With previous pregnancies, $n(\%)^{\mathrm{b}}$ & $33(47)$ & $24(80)$ & $31(72)$ & 0.002 \\
\hline Diagnosis early in pregnancy, $n(\%)$ & $3(4)$ & $2(6)$ & $21(49)$ & $<0.0005$ \\
\hline $\mathrm{HbA}_{1 \mathrm{c}}(\%)$ & $4.1(0.48)$ & $4.2(0.52)$ & $4.5(0.51)$ & 0.0001 \\
\hline Birthweight (kg) & $3.6(0.62)$ & $3.7(0.51)$ & $3.7(0.56)$ & 0.4 \\
\hline Pregnancy $>37$ weeks, $n(\%)$ & $62(89)$ & $30(97)$ & $36(84)$ & 0.064 \\
\hline Insulin-treatment in pregnancy, $n(\%)$ & $1(1)$ & $5(16)$ & $13(30)$ & $<0.0005$ \\
\hline GAD-antibody-positive anytime, $n(\%)$ & $4(6)$ & $2(6)$ & $2(5)$ & 1 \\
\hline Diagnostic OGTT glucose $(\mathrm{mmol} / \mathrm{l})^{\mathrm{c}}$ & $9.4(9.1-9.8)$ & $9.5(9.2-10.1)$ & $9.8(9.3-10.8)$ & 0.004 \\
\hline \multicolumn{5}{|l|}{ Repeated OGTT glucose (mmol/l) } \\
\hline Fasting & $4.3(3.9-4.7)$ & $4.3(3.9-4.9)$ & $5.2(4.4-5.6)$ & 0.0004 \\
\hline $1 \mathrm{~h}$ & $9.2(8.2-10.1)$ & $9.2(8.1-10)$ & $9.9(8.8-10.8)$ & 0.19 \\
\hline $2 \mathrm{~h}$ & $7.8(6.9-9.2)$ & $7.9(7.4-8.7)$ & $8.9(8-10.1)$ & 0.005 \\
\hline \multicolumn{5}{|l|}{ Repeated OGTT serum insulin (pmol/l) } \\
\hline Fasting & $54(39-81)$ & $62(38-114)$ & $61(39-72)$ & 0.76 \\
\hline $1 \mathrm{~h}$ & $402(288-492)$ & $369(272-455)$ & $246(204-312)$ & 0.0004 \\
\hline $2 \mathrm{~h}$ & $457(272-564)$ & $456(329-608)$ & $324(263-450)$ & 0.09 \\
\hline HOMA beta cell & $143.4(104.2-245.6)$ & $134.6(98.9-219.1)$ & $92.4(66.2-135.5)$ & 0.0012 \\
\hline HOMA-IR & $1.8(1.4-3.0)$ & $2.4(1.3-3.8)$ & $2.4(1.5-3.2)$ & 0.45 \\
\hline Insulinogenic index & $4.4(3.0-6.0)$ & $2.9(2.1-4.7)$ & $2.6(1.7-3.4)$ & 0.0012 \\
\hline Disposition index & $2.2(1.1-3.4)$ & $1.8(1.0-2.4)$ & $1.0(0.7-1.7)$ & 0.01 \\
\hline
\end{tabular}

Data are $n(\%)$, means (SD) or median (interquartile range). Differences in means (medians) were tested by ANOVA (Kruskal-Wallis). Frequency differences were tested by Fisher's exact test

${ }^{\text {a }}$ First-degree relatives

${ }^{\mathrm{b}}$ One or more pregnancies

${ }^{\mathrm{c}} 2 \mathrm{~h}$ glucose

HOMA-IR, HOMA of insulin resistance 
Table 2 Comparison of follow-up data at 1 and 2 years postpartum with respect to glucose tolerance at 5 years postpartum

\begin{tabular}{|c|c|c|c|c|}
\hline \multirow[t]{2}{*}{ Characteristics per time postpartum } & \multicolumn{3}{|c|}{ Values per group at 5 years postpartum } & \multirow[t]{2}{*}{$p$ value } \\
\hline & NGT & IGT-IFG & Diabetes mellitus & \\
\hline \multicolumn{5}{|l|}{$n$} \\
\hline 1 year & 57 & 23 & 30 & \\
\hline 2 years & 41 & 24 & 19 & \\
\hline \multicolumn{5}{|l|}{ BMI $\left(\mathrm{kg} / \mathrm{m}^{2}\right)$} \\
\hline 1 year & $24.6(4.6)$ & $27.2(4.6)$ & $29.1(4.8)$ & 0.0001 \\
\hline 2 years & $23.0(20.8-25.7)$ & $27.0(23.1-30.5)$ & $29.8(25.8-34.2)$ & 0.0001 \\
\hline \multicolumn{5}{|l|}{ WHR } \\
\hline 1 year & $0.80(0.74-0.83)$ & $0.81(0.77-0.85)$ & $0.84(0.79-0.89)$ & 0.033 \\
\hline 2 years & $0.78(0.06)$ & $0.81(0.06)$ & $0.85(0.07)$ & 0.0009 \\
\hline \multicolumn{5}{|l|}{$\mathrm{HbA}_{1 \mathrm{c}}(\%)$} \\
\hline 1 year & $4.1(0.26)$ & $4.2(0.40)$ & $4.8(0.56)$ & $<0.00005$ \\
\hline 2 years & $4.1(0.33)$ & $4.4(0.37)$ & $4.6(0.46)$ & $<0.00005$ \\
\hline \multicolumn{5}{|l|}{ Serum cholesterol (mmol/l) } \\
\hline 1 year & $4.3(3.6-5.0)$ & $4.4(4.1-5.1)$ & $4.8(4.2-5.5)$ & 0.06 \\
\hline 2 years & $4.4(4.1-4.6)$ & $3.9(3.6-5.0)$ & $4.8(4.5-5.2)$ & 0.06 \\
\hline \multicolumn{5}{|l|}{ HDL (mmol/l) } \\
\hline 1 year & $1.3(1.1-1.5)$ & $1.2(1.1-1.4)$ & $1.2(1.1-1.5)$ & 0.67 \\
\hline 2 years & $1.3(0.2)$ & $1.2(0.2)$ & $1.2(0.3)$ & 0.09 \\
\hline \multicolumn{5}{|l|}{ LDL (mmol/l) } \\
\hline 1 year & $2.8(0.7)$ & $2.8(0.7)$ & $3.0(0.9)$ & 0.53 \\
\hline 2 years & $2.7(0.7)$ & $2.8(0.9)$ & $3.1(0.6)$ & 0.25 \\
\hline \multicolumn{5}{|l|}{ Triacylglycerol (mmol/l) } \\
\hline 1 year & $0.8(0.6-1.1)$ & $1.0(0.7-1.4)$ & $1.1(0.8-1.8)$ & 0.04 \\
\hline 2 years & $0.8(0.6-1.0)$ & $0.8(0.7-1.2)$ & $1.4(1.0-2.0)$ & 0.0008 \\
\hline \multicolumn{5}{|l|}{ Urate $(\mu \mathrm{mol} / \mathrm{l})$} \\
\hline 1 year & $258(221-278)$ & $229(206-282)$ & $276(240-333)$ & 0.02 \\
\hline 2 years & $261(225-288)$ & $245(225-285)$ & $303(287-324)$ & 0.002 \\
\hline \multicolumn{5}{|l|}{ Fasting glucose $(\mathrm{mmol} / \mathrm{l})$} \\
\hline 1 year & $5.0(0.48)$ & $5.2(0.60)$ & $5.8(1.0)$ & $<0.00005$ \\
\hline 2 years & $5.0(4.8-5.1)$ & $5.5(4.85-5.8)$ & $5.7(5.4-6.2)$ & 0.0001 \\
\hline \multicolumn{5}{|l|}{2 h glucose $(\mathrm{mmol} / \mathrm{l})$} \\
\hline 1 year & $6.1(1.4)$ & $7.0(1.2)$ & $9.8(3.3)$ & $<0.00005$ \\
\hline 2 years & $6.2(1.3)$ & $6.5(1.1)$ & $10.1(3.7)$ & $<0.00005$ \\
\hline \multicolumn{5}{|l|}{ IGT-IFG } \\
\hline 1 year & $15 / 3$ & $16 / 2$ & $11 / 0$ & \\
\hline 2 years & $13 / 1$ & $11 / 5$ & $3 / 1$ & \\
\hline \multicolumn{5}{|l|}{ HOMA beta cell } \\
\hline 1 year & $56(42-86)$ & $62(49-104)$ & $70(46-107)$ & 0.62 \\
\hline 2 years & $64.8(44.4-99.8)$ & $83.4(39.2-102.0)$ & $72.1(48.4-96.4)$ & 0.96 \\
\hline \multicolumn{5}{|l|}{ HOMA-IR } \\
\hline 1 year & $1.6(1.1-2.1)$ & $2.0(1.4-2.9)$ & $2.6(1.7-3.7)$ & 0.0003 \\
\hline 2 years & $1.7(1.1-2.2)$ & $3.2(1.5-4.4)$ & $3.8(2.3-4.3)$ & 0.03 \\
\hline \multicolumn{5}{|l|}{ Insulinogenic index } \\
\hline 1 year & $9.1(4.9-13.8)$ & $8.3(5.1-16.8)$ & $5.5(4.3-7.7)$ & 0.08 \\
\hline 2 years & $9.2(6.3-15.7)$ & $10.8(5.5-15.2)$ & $5.5(3.8-8.5)$ & 0.02 \\
\hline \multicolumn{5}{|l|}{ Disposition index } \\
\hline 1 year & $6.1(3.7-8.4)$ & $3.9(3.4-5.1)$ & $1.7(1.2-4.7)$ & 0.0003 \\
\hline 2 years & $6.1(3.7-8.2)$ & $3.5(2.4-6.6)$ & $1.7(1.0 .2 .3)$ & 0.0001 \\
\hline
\end{tabular}

Data are $n$, means (SD) or median (interquartile range). Differences in means (medians) were tested by ANOVA (Kruskal-Wallis) HOMA-IR, HOMA of insulin resistance 
for differences between medians (non-symmetrically distributed variables). $\chi^{2}$ tests (Pearson) or Fisher's exact tests were used to compare group frequencies.

Multivariate logistic regression with backward elimination and a retention $p$ value of $<0.05$ was used to assess association with development of future manifest diabetes and risk factors assessed during the pregnancy. These risk factors were: fasting blood glucose, $\mathrm{HbA}_{1 \mathrm{c}}$, first-degree family history of diabetes, ethnicity, previous pregnancies, BMI and age. Odds ratios were expressed per SD increment in the respective continuous covariate.

\section{Results and discussion}

The 5-year flow chart of the study population and results is presented in Fig. 1.

The study population was divided into three groups with respect to glucose tolerance at 5 years: (1) NGT; (2) impaired glucose tolerance (IGT) and/or impaired fasting glucose (IFG); and (3) diabetes mellitus. Characteristics during pregnancy are presented in Table 1. Comparison of baseline data was made between the NGT group and the diabetes mellitus group, as well as the NGT group and IGTIFG group. Women who developed diabetes during followup had higher fasting glucose and $\mathrm{HbA}_{1 \mathrm{c}}$ at inclusion than those who stayed normoglycaemic. They also had lower HOMA beta cell index, insulinogenic index and disposition index. Women who developed postpartum diabetes required insulin more frequently during pregnancy than those who remained NGT ( $30 \%$ vs $1 \%)$. There were more women of non-Nordic than Swedish origin $(65 \%$ vs $41 \%)$ in the groups with abnormal glucose tolerance.

In a multivariate logistic regression analysis, variables independently associated with diabetes postpartum were previous pregnancies (OR 4.3, $p=0.018$ ), first-degree family history of diabetes (OR 4.1, $p=0.025), \mathrm{HbA}_{1 \mathrm{c}}(\mathrm{OR}$ 2.6, $p=0.012$ ) and fasting glucose (OR 2.1, $p=0.038$ ) during pregnancy. In addition to a model including only main effects, we also tested for an interaction between $\mathrm{HbA}_{1 \mathrm{c}}$ and fasting glucose. However, this interaction was non-significant (OR 1.0, $p=0.985)$. Previous pregnancies (OR 4.1, $p=0.025$ ) and ethnicity (OR 3.1, $p=0.047$ ) were the variables independently associated with IGT-IFG postpartum.

$\mathrm{HbA}_{1 \mathrm{c}}$ and fasting glucose during pregnancy were grouped into quartiles. Medians (range) for $\mathrm{HbA}_{1 \mathrm{c}}(\%)$ in the respective quartile were: $3.8(2.6-3.9)(n=48), 4.1(4.0-4.2)$ $(n=27), 4.4(4.3-4.6)(n=29)$ and $5.0(4.7-5.4)(n=32)$. The corresponding data for fasting blood glucose $(\mathrm{mmol} / \mathrm{l})$ were: $3.8(3.0-3.95)(n=30), 4.2(4.0-4.35)(n=29), 4.7(4.4-5.1)$ $(n=26)$ and $5.45(5.15-7.4)(n=28)$. A logistic regression analysis testing the predictive value of $\mathrm{HbA}_{1 \mathrm{c}}$ and fasting glucose quartiles on 5 year diabetes risk showed that individuals with $\mathrm{HbA}_{1 \mathrm{c}}$ or fasting glucose in quartile 4 had a 4.8 -fold $(p=0.00014)$ and 6.8 -fold $(p=0.00002)$ increased risk of postpartum diabetes respectively compared with women from quartiles 1 to 3 .

Results from the 1 and 2 year follow-up are shown in Table 2. Women with abnormal glucose tolerance after 5 years had higher BMI and WHR than those with NGT. HOMA beta cell index did not differ between the groups, but the insulinogenic index was lower among women who had developed diabetes after 5 years, especially when adjusted for degree of insulin resistance. Cholesterol levels were similar in all three groups, while urate concentrations were higher in the diabetes group than in the other groups.

Median (interquartile range) for BMI at study end was 24.3 (21.4-28.1) in the NGT group, 26.6 (23.6-30.7) in the IGT-IFG group and $28.7(24.2-33.1)$ in the diabetes group $(p=0.0053)$.

To our knowledge, this is the first study to report $\mathrm{HbA}_{1 \mathrm{c}}$ as a predictor of diabetes after gestational diabetes mellitus. Although $\mathrm{HbA}_{1 \mathrm{c}}$ is a valuable test in monitoring treatment of diabetes, it has not been advocated for diagnostic purposes due to lack of uniform standardisation. However, these limitations have now been addressed and programs for standardisation of $\mathrm{HbA}_{1 \mathrm{c}}$ assays have been established [12]. The results of the Swedish Mono S method can be converted to the National Glycohemoglobin Standardization Program (NGSP) standard by the following equation: $0.923 \times \mathrm{HbA}_{1 \mathrm{c}}($ MonoS $)+1.345=\mathrm{HbA}_{1 \mathrm{c}}(\mathrm{NGSP})$. On the other hand, fasting glucose as a risk factor for diabetes after gestational diabetes mellitus has been extensively studied [2]. Our results, showing that a fasting blood glucose concentration $\geq 5.2 \mathrm{mmol} / \mathrm{l}$ was associated with a sixfold increased risk of postpartum diabetes, are in line with previous reports $[13,14]$.

To conclude, our findings suggest that $\mathrm{HbA}_{1 \mathrm{c}} \geq 4.7 \%$ (Swedish Mono S, equivalent to $\geq 5.7 \%$ NGSP) and fasting blood glucose $\geq 5.2 \mathrm{mmol} / 1$ are associated with a four- to sixfold increased risk of developing diabetes within 5 years after gestational diabetes mellitus. Such information could easily be obtained during the diagnosis and treatment of gestational diabetes mellitus. Counselling and education on future diabetes risk and care could then be initiated during pregnancy in high-risk individuals.

Acknowledgements This study was supported by the Zoégas Foundation, Lundström Foundation, Research Funds of Malmö University Hospital and by grants from County of Skåne. We acknowledge Y. Wessman and V. Gunnarsson for skilful technical assistance.

Duality of interest The authors declare that there is no duality of interest associated with this manuscript. 


\section{References}

1. Anderberg E, Kallen K, Berntorp K, Frid A, Aberg A (2007) A simplified oral glucose tolerance test in pregnancy: compliance and results. Acta Obstet Gynecol Scand 86:1432-1436

2. Kim C, Newton KM, Knopp RH (2002) Gestational diabetes and the incidence of type 2 diabetes: a systematic review. Diabetes Care 25:1862-1868

3. Ben-Haroush A, Yogev Y, Hod M (2004) Epidemiology of gestational diabetes mellitus and its association with type 2 diabetes. Diabet Med 21:103-113

4. Dornhorst A, Rossi M (1998) Risk and prevention of type 2 diabetes in women with gestational diabetes. Diabetes Care 21 (Suppl 2):B43-B49

5. Lind T, Phillips PR (1991) Influence of pregnancy on the 75-g OGTT. A prospective multicenter study. The Diabetic Pregnancy Study Group of the European Association for the Study of Diabetes. Diabetes 40(Suppl 2):8-13

6. Matthews DR, Hosker JP, Rudenski AS, Naylor BA, Treacher DF, Turner RC (1985) Homeostasis model assessment: insulin resistance and beta-cell function from fasting plasma glucose and insulin concentrations in man. Diabetologia 28:412-419

7. Phillips DI, Clark PM, Hales CN, Osmond C (1994) Understanding oral glucose tolerance: comparison of glucose or insulin measurements during the oral glucose tolerance test with specific measurements of insulin resistance and insulin secretion. Diabet Med 11:286-292
8. No authors listed (1999) Definition, diagnosis and classification of diabetes mellitus and its complications. Part 1: diagnosis and classification of diabetes mellitus. Report of a WHO consultation. WHO, Geneva

9. Jeppsson JO, Jerntorp P, Sundkvist G, Englund H, Nylund V (1986) Measurement of hemoglobin A1c by a new liquidchromatographic assay: methodology, clinical utility, and relation to glucose tolerance evaluated. Clin Chem 32:1867-1872

10. Friedewald WT, Levy RI, Fredrickson DS (1972) Estimation of the concentration of low-density lipoprotein cholesterol in plasma, without use of the preparative ultracentrifuge. Clin Chem 18:499-502

11. Tuomi T, Carlsson A, Li H et al (1999) Clinical and genetic characteristics of type 2 diabetes with and without GAD antibodies. Diabetes 48:150-157

12. Hoelzel W, Weykamp C, Jeppsson JO et al (2004) IFCC reference system for measurement of hemoglobin A1c in human blood and the national standardization schemes in the United States, Japan, and Sweden: a method-comparison study. Clin Chem 50:166-174

13. Metzger BE, Cho NH, Roston SM, Radvany R (1993) Prepregnancy weight and antepartum insulin secretion predict glucose tolerance five years after gestational diabetes mellitus. Diabetes Care 16:1598-1605

14. Schaefer-Graf UM, Buchanan TA, Xiang AH, Peters RK, Kjos SL (2002) Clinical predictors for a high risk for the development of diabetes mellitus in the early puerperium in women with recent gestational diabetes mellitus. Am J Obstet Gynecol $186: 751-756$ 